\title{
Hallucinatory and Verbal Modes of Thinking
}

\author{
Manuel Batsch ${ }^{1}$ \\ University College London
}

\begin{abstract}
At the beginning of Freud and the Scene of Writing Derrida announced the way he would use Freud: "to locate in Freud's texts (...) those elements of psychoanalysis which can only uneasily be contained within logocentric closure" (Derrida, 1978, p. 249). In this paper I want to take over Derrida's reading angle under the form of a question: the question of what escapes the logos in Freud's work?

I tackle this question at two different levels:

1. The level of Freud's model: in Freud's model of the psyche what are the modes of functioning that cannot be verbalized?

2. The level of Freud's formulation: in Freud's writings what is not exclusively formalized under a verbal form?

In the first part I identify within the hypothesis that Freud imagined to describe the genesis of the psyche: a primary hallucinatory mode of thinking and a secondary verbal mode of thinking. I try to show how the creation of unconscious presentations by the hallucinatory mode of thinking operates beyond the logos. Moreover I propose that meaning produced by the verbal mode of thinking covers and hides the hallucinatory mode of thinking, which would constitute a form of functioning of repression. In the second part I try to define the ways Freud invented a form of writing in order to model hallucinatory modes of thinking. I propose to name metapsychological writing this form of writing that uses scientific formulations, graphics, analogies and myths. I argue that what is at stake in the invention of a metapsychological writing is the creation of a conceptual framework to express clinical phenomena specific to psychoanalysis.
\end{abstract}

\section{Introduction}

The question I would like to raise in this paper comes from Jacques Derrida. With $O f$ Grammatology Derrida undertook one of his main philosophical endeavours: to challenge what makes objectivity possible, "the originary constitution of objectivity" (Derrida, 1976, p. 88). Derrida searches an alternative to a philosophy of consciousness and intentionality, which "from Descartes to Hegel" apprehend "presence as consciousness,

${ }^{1}$ Correspondence concerning this article should be addressed to Manuel Batsch.

E-mail: manuelbatsch@yahoo.fr 
self-presence conceived within the opposition of consciousness to unconsciousness" (Derrida, 1978, p. 248). But in his escape from 'the cogito', Derrida's aim is also to overcome structuralism. Indeed in Of Grammatology Derrida argues that notions of sign and signifier have a fundamental link with Western metaphysic. By using the sign to reach objectivity, structuralism limits "the sense of being within the field of presence" under "the domination of a linguistic form" (Derrida, 1976, p. 23). In structuralism's view objectivity becomes what in the object subjects itself to the sign (Safatle, 2011). In his criticism of an objectivity defined around reason or defined around linguistic structures, Derrida identified Freud as an ally. Derrida finds in Freud's model of the unconscious intentional processes beyond consciousness, which seem to play a part in the constitution of objectivity. Contrary to Lacan, Derrida thinks that those unconscious processes cannot be apprehended through structuralism. In Derrida's view, the language of the unconscious described by Freud isn't organized around the notion of sign. To describe this language of the unconscious Derrida invents the term psychical writing. Thus objectivity would have its roots in "psychical writing", a language that functions beyond the sign and beyond self-presence. This use of Freud comes from a reading that Derrida summarized very clearly at the beginning of Freud and the Scene of Writing: "Our aim is limited: to locate in Freud's texts (...) those elements of psychoanalysis which can only uneasily be contained within logocentric closure" (Derrida, 1978, p. 249).

It is this aim of Derrida's in his reading of Freud that I would like to take over under the form of a question - the question of what escapes the logos in Freud's work? I think that this question has a great significance beyond the use that Derrida made of it for his own researches. My aim is to use this question to understand what is at stake in Freud's metapsychology. I would like to propose that Freud's metapsychology describes the evolution from a mode of thinking that cannot be reduced to the logos towards a verbal mode of thinking. According to this hypothesis metapsychology would give a model of the genesis of the mental apparatus and its functioning through the cohabitation of two modes of thinking: a primary hallucinatory mode of thinking and a secondary verbal mode of thinking.

Hence, my starting point will be the question of understanding what cannot be verbalized in Freud's work. But this question can be read at two different levels:

1. The question can be understood at the level of Freud's model: in Freud's model of the psyche what are the modes of functioning that cannot be expressed through words?

2. The question can be understood at the level of Freud's formulation: in Freud's writings what is not exclusively formalized under a verbal form?

The two aspects of the question are in fact linked. It is precisely because Freud identified mode of functioning of the psyche that are non-verbal, that he felt the need to theorize them under a non-exclusive verbal form. However in this paper I will deal with the two aspects of the questions separately.

Firstly I will try to show how Freud's metapsychology is an account of a psychical apparatus that generates a primitive hallucinatory mode of thinking and a secondary verbal mode of thinking. 
Secondly I will attempt to understand the way Freud's writing is distorted by the modelling of a mode of thinking beyond the logos.

\section{To verbalize is to repress}

In the last part of his paper The Unconscious, Freud proposed that the character of strangeness attributed to schizophrenic symptoms in comparison with symptoms found in transference neurosis comes from the schizophrenic's use of words (p. 200). Words that compose the speech of the schizophrenic are used in the hallucinatory grammar of dreams: the primary psychical process made of condensations and displacement. Hence the impression of strangeness comes from the hybrid nature of the schizophrenic language that hallucinates words or, to use Freud's metapsychological code, that treats words-presentation like thing-presentation. In "schizophrenia object-cathexes are given up" but "the cathexis of the word-presentation is retained" (Freud, 1915c, p. 201) and therefore words seem invaded by an unconscious mode of functioning. These 'schizophrenic' utterances or the way "the dream-work occasionally treats words like things" lead to the idea that "the conscious presentation comprises the presentation of things plus the presentation of the word belonging to it, while the unconscious presentation is the presentation of the thing alone" (Freud, 1915c, p. 201)

This conception of the system unconscious populated by 'thing presentations' functioning in a hallucinatory mode of thinking goes way beyond a reductionist hermeneutic view of the unconscious. A hermeneutic model would reduce the unconscious to a container of hidden meanings: the unconscious understood as a psychic store of repressed mental contents that would be accessible only through the analytical process. Against such a view Freud's papers on metapsychology of 1915 present the unconscious as a system that generate a hallucinatory mode of thinking. At the core of the description of this unconscious mode of thinking is to be found the paradoxical notion of 'unconscious presentation'. The German word for 'presentation' is 'Vorstellung'. In the standard edition James Strachey has translated it by 'idea' or by 'presentation'. In this paper I will translate 'Vorstellung' only by 'presentation', which seems to me more faithful to the philosophical origins of the word. Indeed 'Vorstellung' is a key concept of Kantian and post-Kantian philosophy. Ola Anderson pointed out the possible influence that the notion of 'mechanic of presentation' developed by Johann Friedrich Herbart may have had on Freud (Anderson, 1962, p. 224). But even more that Herbart it is from Franz Brentano that Freud took on the notion of presentation and more generally the philosophical assumption "that every mental state can be analyzed into two components": a presentation and its charge of affect (Wollheim, 1991, p. 35). In Brentano's view a 'presentation' is not a psychical content, not the idea derived from an object but the perception of the object in its actuality: the 'presentation' is not the colour but the vision of the colour (Merleau-Ponty, 1956, p. 1293). This understanding of presentation remains empirical since a presentation is the outcome of the world as perceived by the senses. Brentano's concept of presentation prefigures much more Husserl's phenomenology than Freud's metapsychology. Indeed Freud used the concept of 'presentation' in a completely original way that led him to this specifically Freudian notion of 'unconscious 
presentation' $^{2}$ : not a deeply buried memory trace but a mental processes of a different nature. A mental process that is not a perception but a transformation of the object and whose functioning draws the outlines of psychical reality. Freud's metapsychological texts propose a "fiction" that describes the genesis of the structure and function of the mental apparatus. In this fiction "at the beginning of our mental life we did in fact hallucinate the satisfying object when we felt the need for it" (Freud, 1917, p. 231). Hence according to Freud, the hallucinatory perception of reality that appears in dreams or in hypnosis is also the way through which psychic life begins and what "once dominated waking life, while the mind was still young and incompetent, seems now to have been banished into the night (...). Dreaming is a piece of infantile mental life that has been superseded" (Freud, 1900, p. 567). ${ }^{3}$ Through this primary hallucinatory mode of thinking a biological need is transformed into a psychical wish. The mnemic image linked with the object subjectively perceived in 'the experience of satisfaction' of a need is reinvented under the form of a presentation in the hallucinatory experience of the wish. As a consequence, psychical reality must be distinguished from the subjective perception of material reality. Jean Laplanche proposed to name the latter 'psychological reality' (Laplanche, 1993, p. 77). Freud usually distinguishes two levels of reality: psychical reality and material reality. To add this third level of 'psychological reality' clarifies the specificity of psychical reality. The 'object' belongs to material reality. The subjective 'mnemic image' attached to the perception of the object belongs to psychological reality. The 'presentation', which is the result of the 'mnemic image' reinvented through a hallucinatory mode of thinking, belongs to psychical reality. Psychical reality transforms the subjective perception of material reality into a hallucinatory unconscious reality. What motivates this transformation is not the perception of the external world but this psychical force that Freud named the Trieb, the drive. The drive is this force "lying on the frontier between the mental and the physical" that put the mind at work (Freud, 1905, p. 168). Thus with the notion of 'thing-presentation' that results from a hallucinatory act of creation, Freud described a "psychical writing" that functions beyond consciousness, beyond self-presence. Psychical reality is the outcome of this "psychical writing": the outcome of a hallucinatory mode of thinking that escapes consciousness.

The knowledge drawn upon by Freud from dream, infancy and madness demonstrates the hallucinatory core of the psychic apparatus. The first kind of mental process is the unconscious mental processes. In Freud's metapsychological account, in the beginning was the unconscious, primary consciousness being reduced to sense organ monitoring the psychical qualities of pleasure and unpleasure: it "is probable that thinking was originally unconscious (...) and that it did not acquire further qualities, perceptible to consciousness, until it became connected with verbal residues" (Freud, 1911, p. 221). A mode of thinking of consciousness emerges from a verbal mode of thinking: the capacity for an idea to be connected with verbal presentation "whose residues of quality are

\footnotetext{
${ }^{2}$ Freud takes over major philosophical concepts in a curious way: as if he was making illegitimate children with the philosophers from whom he borrows concepts.

${ }^{3}$ Thus a dream is not only a way to reveal repressed wishes through its analysis but also an expression of the most primitive way of thinking.
} 
sufficient to draw the attention of consciousness to them and to endow the process of thinking with a new mobile cathexis from consciousness" (Freud, 1900, p. 617).

I would like to put forward the hypothesis that this verbal mode of thinking specific to consciousness covers and hides the hallucinatory mode of thinking specific to the system unconscious. I propose to think of repression in the light of this hypothesis. In his paper on Repression Freud indicated, "repression is not a defensive mechanism which is present from the beginning, and that it cannot arise until a sharp cleavage has occurred between conscious and unconscious mental activity" (Freud, 1915b, p. 147). Since conscious mental activity is characterized by a verbal mode of thinking, Freud's statement can be rewritten: "repression cannot arise until the acquisition of a verbal mode of thinking". 4 Hence primal repression: the first phase of repression, "which consist in the psychical" representative of the drive "being denied entrance into the conscious" corresponds to thoughts that cannot be connected with verbal presentations and as a consequence these thoughts exist only under a hallucinatory form.

A primitive hallucinatory mode of thinking and a secondary verbal mode of thinking cohabitate in the human psyche, but those two modes of thinking are not in a one-to-one correspondence. I propose that the censorship exercised by primal repression is not a matter of moral but rather the outcome of the irreducibility between two modes of thinking: because of the limits of language, some thing-presentations are caught in a hallucinatory mode of thinking. Presentations that cannot be expressed in the language of consciousness establish in the mental apparatus 'fixations' of very primitive thoughts primitive not only because of the hallucinatory mode of thinking that produced them but also because of the bodily aspects of these thoughts. Infantile fixations in the unconscious are hallucinations produced by the anus, the mouth, the genitals and any regions of the body that can operate as an erotogenic zone. The various libidinal stages would correspond to the erotogenic zones through which thing-presentations are hallucinated. The infant would create presentations from memory traces of the external objects through specific erotogenic parts of its body. Hence the hallucinatory mode of thinking is closely linked with infantile sexuality because it is produced from parts of the body that are capable of producing sexual excitations. The connection between the primitive hallucinatory mode of thinking and infantile sexuality has also an exogenous origin. Through the care carried by the adult, the infant also receives elements of the adult's sexuality. Not only a set of erotogenic stimulus (made of rubbings, of quivering, of smells, of warmth...) but also, in a more enigmatic way, the infant receives something of the conscious and unconscious fantasies through which the adult invests his/her own body. The hallucinatory presentations created from parts of the adult's body involves in a complex way the different stimuli and messages received from the adult. ${ }^{5}$ The infant

\footnotetext{
${ }^{4}$ Before this stage the defensive mechanisms have a hallucinatory nature that have been first explored by Melanie Klein.

${ }^{5}$ Jean Laplanche has developed his general theory of seduction from the idea that the sexual message originating in the adult is an enigmatic message for the infant. With this theory Laplanche proposes an account of the origin of the psychic apparatus and the drives, starting from the adult-infant relation.
} 
creates presentations hallucinated on the body through auto-erotism. In such a way that auto-erotism is paradigmatic of the hallucinatory mode of thinking. Infantile sexuality, which is at the core of the hallucinatory mode of thinking is incompletely transposed in the verbal mode of thinking. The auto-erotic activity bears witness to the incapacity of a verbal mode of thinking to link sexual thing-presentations to word-presentations. It is because some presentations of infantile sexuality are fixated under a hallucinatory form that the sexual drive is so to speak 'obliged' to behave auto-erotically at first. The hallucinatory mode of thinking is performative, what is thought is created: "unconscious processes (...) equate reality of thought with external actuality, and wishes with their fulfilment (Freud, 1911, p. 225). Thing-presentations created by the hallucinatory mode of thinking generate a reality: the psychical reality. Hence those presentations have a psychical truth-value. For that reason the presentations produced by the hallucinatory mode of thinking are similar to the suggestions that the hypnotized receives from the hypnotist. The state of hypnosis put forward a hallucinatory mode of thinking and the hypnotized understands the messages from the hypnotist as orders. It is as if at the centre of the self, was to be found a hypnotist who produces suggestions. Except that this hypnotist who sits at the core of the self would use the enigmatic language of unconscious presentations.

Presentations that exist only under a hallucinatory form create a terrifying world in which thoughts are omnipotent. Unconscious presentations of infantile sexuality are like suggestions experienced on the one hand in a hallucinatory way on the body through auto-erotism. On the other hand infantile sexuality is experienced in the language as an eternal quest for meaning, which is expressed with such an acute intensity in children's sexual curiosity that Freud "considered giving this epistemophilic urge the status of a separate drive" (Temperley, 2005, p. 62). An effect of this curiosity that motivates the child to discover answers in language is to hide the hallucinatory nature of the sexual wish. In the same way one of the functions of masturbatory scenarios built by the adult is to create a meaning that covers the hallucinatory noise of the sexual wish. The psychical apparatus generates: a hallucinatory mode of thinking whose characteristic is to be performative and a verbal mode of thinking whose characteristic is to bring meaning. What comes first is the demand of the unconscious wish that result from the hallucinatory mode of thinking. Meaning is brought secondarily in the après-coup of the hallucinatory wish as a way to hide the hallucinatory nature of the wish. In this perspective one of the psychical functions of verbal language is to produce meaning that would, in the aprèscoup, conceal the hallucinatory nature of wishes. I propose to understand this masking function of verbal language as a repression après-coup, an 'after-repression'.

A metapsychological perspective has revealed a system unconscious that does not work on the mode of the logos: a system unconscious understood not as a receptacle of hidden meaning but rather as a creator of illusions. Illusions generated by thing-presentations created through a hallucinatory mode of thinking. I propose to think of repression as the outcome of the superimposition between this hallucinatory mode of thinking and the verbal mode of thinking of consciousness. Primary repression results from the irreducibility between the hallucinatory mode of thinking and the verbal mode of thinking and as a result some presentations are fixed in the system unconscious. It would be around these fixations that we hallucinate reality subjectively perceived. The meaning 
produced by verbal thoughts would conceal those hallucinations from consciousness. Verbal language generates meanings as an après-coup of a hallucinatory psychical reality. Meaning produced by consciousness is in the après-coup of unconscious wishes. Derrida identified this aspect of Freud's model and used it against an objectivity that would be subjected to a metaphysic of presence. In fact the repressive function of the logos in Freud would rather open the possibility of an objectivity of the absence. The performative aspect of the hallucinatory mode of thinking and the enigmatic nature of the unconscious presentations mean that unconscious wishes open up a breach in the subject. Quest for meaning would rather consist in a perpetual race behind this absence that unconscious wishes open up in the self: "signified presence is always reconstituted by deferral, nachträglich, belatedly, supplementarily: for the nachträglich also means supplementary" (Derrida, 1978, p. 266). I believe that Derrida formed his alliance with Freud around a conception of the logos that is not in the field of presence: logos as marked by the après-coup - logos as secondary to an enigmatic psychical writing, ${ }^{6}$ that I have tried to define in this paper as a hallucinatory mode of thinking.

\section{A metapsychological writing}

The idea that meaning generated by verbal language achieves a repressive function is not only a theoretical one. It has, in fact, a very direct application in the analytical practice. The fundamental rule of the psychoanalytic cure: the rule of free association, "which lays it down that whatever comes into one's head must be reported without criticizing it" (Freud, 1912, p. 107) is a method to verbalize beyond the logos. Likewise on the side of the analyst this unusual way to listen, which consist in not directing the attention to anything particular, the so-called 'evenly suspended attention' is a way to listen beyond conscious meaning. The psychoanalytic technique endeavours to trap verbal language in order to bypass its repressive function. The aim of this technique is to generate a dialogue that challenges the repressive aspect of verbal meaning. As a consequence the defence mechanisms that rest on verbal narratives are somewhat thwarted by the analytical framework. Therefore more primitive defence mechanisms may manifest themselves in the analysis.

These primitive defence mechanisms - of which Freud gave an outline: "reversal into the opposite or turning round the subject's own self" (Freud, 1915b, p. 147) - are of a hallucinatory nature. I think that these hallucinatory mechanisms of defence appear on the analytical scene through what Freud had described in his letter to Groddeck as "the hubs of treatments": resistance and transference.

Firstly I will try to show how hallucinatory mechanisms can manifest themselves through resistance to the rule of free association. The stroke of genius of The Interpretation of Dreams is to establish "in the face of 'scientific' prejudices" that manifestations of the unconscious - dream, parapraxis, symptoms, free association - have significance: they

${ }_{6}$ One of Derrida's axioms is that a form of writing is a requirement for speech and that it is precisely the "repression" of this primary form of writing that constitutes the origin of western philosophy as a branch of knowledge. 
obey the laws of the primary process, "which constitute a primary mode of functioning of the logos" (Laplanche Pontalis, 1973, p. 306). A purpose of the analytical framework is to give birth to such productions of the unconscious in order to decipher them. Hence the utopia of free association would consist in a speech guided by the grammar of the primary process: a kind of spoken dream. The rebus constituted by this ideal chain of free association could then be interpreted. In the reality of the practice a constant flow of free associations is an ideal never attained. The speech of the one who free-associates comes up against more or less explicit resistances. I think this resistance to free associations is the expression of psychical phenomena that are not understandable through the primary process. The primary process describes the functioning mechanism of unconscious presentations. What I named hallucinatory mode of thinking describes the hypothetical psychical act that creates unconscious presentations from memory traces. Because this hallucinatory mode of thinking is partly a bodily mode of thinking - as it appears in autoerotism - unconscious presentations resist being verbalized. Thanks to free association the subject reproduces the functioning mechanism of unconscious presentations and the nonverbal aspects of those presentations can thus appear so to speak negatively: the pattern of the resistances to free associations draws the outlines of presentations that are 'unrepresentable' in verbal language. Unconscious phenomena revealed by the psychoanalytic practice, which seem irreducible to a verbal expression, resist the primary process as for instance: resistance to free associations, failure of the dream or acting out.

I propose that non-verbal phenomena also manifest themselves in the clinic through what Freud qualified as "the more specific finding of analytic work" (Freud 1914, p. 112): the transference. I think that it is partly because the analytical framework reduces the censorship of verbal meaning that the analysand hallucinates the analyst. In transference, the meaning of the analyst for the analysand gets lost. ${ }^{7}$ The analysand creates unconscious presentations of the analyst in a similar way to how an infant creates unconscious presentations of the world that surrounds him/her.

The transference and the resistance to the cure replay, in the here and now of the analytic situation, a mode of thinking that was at the origin of psychical reality. Hence, part of the logos gets lost in the analytical encounter. The great specificity of psychoanalytic empiricism is to generate clinical phenomena that operate beyond the logos. It is this peculiarity of the psychoanalytical phenomena that raises so many questions to both the positivist and the hermeneutic tradition. In a way the task of psychoanalysis is not only to study those psychical phenomena but also to invent a framework that can describe them. I believe that it is this very task that Freud addressed by searching a form of writing that

\footnotetext{
${ }^{7}$ As Freud put it: "psycho-analysis does not create it [transference], but merely reveals it to consciousness and gains control of it in order to guide psychical processes towards the desired goal" (Freud, 1910, p. 51). Psychoanalysis doesn't have the monopoly on the phenomena of transference and one experiences it in day-to-day life, especially in situations of love. And certainly novels and plays have described the many ways through which reality of the language gets lost in love. I believe it would be interesting to think of love as a situation that generates a hallucinatory mode of thinking.
} 
would describe psychical events functioning beyond the logos. I propose to call this form of writing, paraphrasing Derrida: a metapsychological writing a metapsychological writing whose purpose would be to transcribe psychical writing.

Anyone, analyst or analysand, who has tried to write the content of a psychoanalytic session, knows how complex an exercise that is. The complexity comes partly from the great heterogeneousness of the analytical material in which becomes intermingled: an event from the day before, a dream, a type of silence, a fantasy, a certain noise, a distant memory and so on... But at a deeper level, I believe it is the nature of some clinical phenomena produced by the analytical encounter that explains this difficulty. The psychoanalytic practice generates phenomena that contain hallucinatory thoughts using the bodily writing of unconscious presentations. Hence to write about an analytical session, one needs a writing that could transcribe this antic hallucinatory non-verbal mode of thinking. I believe that Freud's metapsychology is also an attempt to create such a writing. In Freud's metapsychology, what is at stake behind the hypothesis about a genesis of the unconscious is also the creation of a conceptual framework to express clinical phenomena specific to psychoanalysis. I think that when Freud compared metapsychological analogies to scaffolding (Freud, 1900, p. 536) or when he wrote of metapsychology as "the theoretical assumptions on which a psycho-analytic system could be founded" (Freud, 1917, p. 222, fn 1) he expressed this very issue: the need to create conceptual resources to express the non-verbal phenomena that appear in the clinic. ${ }^{8}$

The exhaustive research of the stratagems Freud invented to write beyond the logos is an extraordinarily complex and rich task. Indeed the problem raised by Freud's metapsychological writing goes beyond the difficulty to formalize knowledge about nonverbal presentation. ${ }^{9}$ What is at stake is the link between a form of writing and the psychoanalytical practice. Hence some aspects of this practice structure this form of writing. In the scope of this paper I would like to draw a first sketch of the metapsychological writing. In order to do so I will mention two aspects of it that are conditioned by the psychoanalytical practice and then two of the main systems used in a metapsychological writing.

\footnotetext{
8 The epistemologist Gilles-Gaston Granger argues that this "conceptual insufficiency" actually constitutes a richness of the psychoanalytic clinic because it raises in a "radical way" the problem of the transposition of a subjective phenomenon into an objective knowledge (G-G Granger, 1967).

${ }^{9}$ The idea that verbal language is incapable of communicating the affects is very much present in Nietzsche: "Our true experiences are not at all garrulous. They could not communicate themselves even if they tried: they lack the right words. We have already gone beyond whatever we have words for" (Twilight of the Idols, "Skirmishes of an Untimely Man" § 26). Patrick Wotling (2008) used this very idea to explains the specificity of Nietzsche's philosophical writing.
} 


\section{An esoteric writing}

Since a characteristic of psychoanalytic objects is the difficulty to prove their existence, a metapsychological writing describes phenomena whose positivist existence remains speculative. What makes the existence of psychoanalytical objects so hard to prove comes partly from the warning that Freud had addressed to his listeners at the beginning of his introduction to psychoanalysis: "The talk of which psycho-analytic treatment consists brooks no listener; it cannot be demonstrated" (Freud, 1915-1916, p. 17). Psychoanalytic clinical phenomena come from a dialogue that cannot be observed without losing its internal truth (Mosès, 2011). Like the phenomena it tries to describe, the first traces of a metapsychological writing appeared in the privacy of a dialogue: the one of the correspondence between Freud and Fliess. Unlike the neologism 'psychoanalysis' that Freud used for the first time in a scientific publication, ${ }^{10}$ Freud created the word 'metapsychology' in a letter to Wilhelm Fliess. ${ }^{11}$ Freud made up this new form of writing in the secrecy of this correspondence and in the intimacy of his selfanalysis. I believe that this esoteric aspect is a first characteristic of Freud's metapsychological writing that is linked with the analytical practice.

\section{A writing of the incomplete}

The second aspect linked with the analytical practice that I would like to stress is the incompleteness of the project elaborated through metapsychological writing. Firstly because metapsychology has constantly to take into account new clinical material. Secondly because when clinical material stops being informative, metapsychology is the only way to carry further the theoretical reflexion. In his introduction to Freud's metapsychological papers Strachey moans the loss the seven metapsychological papers destroyed by Freud: "It is difficult to exaggerate our loss from the disappearance of these papers"(Strachey, p. 106). Together with the five existing papers, they would have made up a comprehensive metapsychological work. ${ }^{12}$ Yet I would argue that the project of an exhaustive description of metapsychological concepts is not conceivable. When Freud speaks of metapsychology as "the furthest goal that psychology could attain" (Freud, 1925 , p. 59) it is, in my opinion, a way to ascribe an asymptotic value to such a goal. In the word metapsychology, "meta" is often understood as designating "beyond" the consciousness. It has been proposed as well that "meta" stands for "beyond" psychology or "beyond" clinical observations (Assoun, 2007). The point I would like to make here is that "meta" can also be interpreted as "beyond" completeness. Metapsychology is therefore a constant work in progress, a place for exploration, something similar to the laboratory of the scientist or the studio of the artist.

\footnotetext{
${ }^{10}$ In a paper published in March 30, 1896 in the Revue Neurologique

${ }^{11}$ Letter of February 13, 1896: "I am continually occupied with psychology really metapsychology".

${ }^{12}$ The book would have been entitled Zur Vorbereitung einer Meta-psychologie (Preliminaries to a Metapsychology).
} 


\section{The three points of view}

In the middle of Freud's major paper on The Unconscious, arises the definition of the metapsychological "way of regarding": the description of "a psychical process in its dynamic, topographical and economic aspects" (Freud, 1915c, p. 181). This definition of a "metapsychological presentation" is in fact extremely radical because each of those three aspects hits an impossibility which is to be named: a limit of the logos.

Freud built the topographical point of view on the idea of psychical localities, which are not determine of in any "anatomical fashion" but rather as the constituents of a "fiction" (Freud, 1900, p. 598) to model our mental functioning: the mental (or psychical) apparatus. The topographical point of view consists in locating a psychical process in the mental apparatus. Precisely because he didn't base the mental apparatus on any anatomical ground, Freud has to invent the geography of the mental apparatus. He cannot refer to any anatomical reality and so he has to draw a new map that corresponds to the dissection of a concept: the one of the mental apparatus. In order to map a psychical process, Freud needs to invent a graphic, such as the graphics that appear in chapter seven of The Interpretation of Dreams. From a textual angle that corresponds to the replacement of writing by drawing. I propose that the replacement of verbal writing by the graphic of a fiction constitutes the topographical limit to the logos.

The dynamic and the economic point of views rest on the ideas of force and energy: psychical processes would be the outcome of forces and they would be cathected by amounts of energies. These two point of views are inspired by physical sciences: the notion of force is at the core of Newtonian mechanics and the one of energy at the core of thermodynamics. For that reason many criticisms have been addressed to the dynamic and the economic point of view arguing that Freud's concern with psychical force or psychical energy was a scientific anachronism (Gedo, 1977). In particular the fact that the medium of psychical force remains unclear and that quantitative changes of psychical energy are impossible to measure in a clinical observation have appeared as "the weakest element" of a dynamic and economic theory of psychological causations (Kubie, 1947). ${ }^{13}$ Against this view I argue that those two points of view are not so much the testimony of Freud's scientism but rather a means to write psychical phenomena in a non verbal way. They both lead toward a mathematical formalization of psychical processes in which forces could be modeled by vectors and energies by numbers. However, unlike some post-Freudian psychoanalytic thinkers such as Lacan or Bion who have proposed mathematical approaches of the psyche, Freud never really went through this path. I nevertheless believe that he initiated it. When he wrote that the economic point of view "endeavours to follow out the vicissitudes of amounts of excitation and to arrive at least

${ }^{13}$ As noticed by Mark Cousins in his introduction of a selection of Freud's theoretical papers: "Within psychoanalysis it is more the idea of the economic dimensions and its relation to the drive that has come in for criticism or simply neglect. Faced with the inexorable progress of measurement within psychology there has been an increasing reluctance to refer to a quantitative dimension within psychical life without being able to assign numbers or measured relations to it" (Mark Cousins, Introduction of The Unconscious, Freud, 1915c, pp. xiv-xv) 
at some relative estimate of their magnitude" (Freud, 1915c, p. 181) one feels a numerical writing looming on the horizon. And yet "the indefiniteness of all our discussions on what we describe as metapsychology (...) due to the fact that we know nothing of the nature of the excitatory process that takes place in the elements of psychical systems" constrains to operate "all the time with a large unknown factor, which we are obliged to carry over into every new formula"(Freud, 1920, pp. 30-31) This unknown factor carried in the economic and dynamic description of a psychical phenomena constitutes, I believe, the economic and dynamic limit to the logos.

Freud's transcription of a psychical process into a metapsychological presentation is not written exclusively under a verbal form. Along the topographical axis it takes the form of a graph and along the economical and dynamic axis it is represented through "formulas" that carry over "a large unknown factor".

\section{The Mythology}

In his quest to formalize unconscious psychical determinism, Freud used the Greek myths. Already at the time of his self-analysis Freud had raised the hypothesis that Oedipus tragedy could seize "on a compulsion which everyone recognises because he feels its existence within himself"14. Then throughout Freud's work, Greek mythology seems to furnish his metapsychology with paradigmatic figures, whose evolution could be summarized around the succession of three of these mythological figures: Oedipus, Narcissus and Thanatos. Oedipus would correspond to the discovery of infantile sexuality, Narcissus to the introduction of the concept of narcissism and Thanatos to the apparition of the death drive. Greek mythology is a fundamental element of Freud's metapsychological writing. In his endeavours to formalize unconscious presentations the logos of a theory of psychological causations is transformed into the pathos of Greek mythology. ${ }^{15}$ Moreover, by writing the subject's psychical reality through the Greek tragedies, Freud gave back a significance to the violence of destiny contained in these myths: the determinism of unconscious presentations disguised in the form of destiny. I believe that the use of mythology is one of the main solutions Freud found to the problem of writing the hallucinatory nature of the unconscious.

\section{Conclusion}

In Character in Fiction a paper given in 1924 before the Cambridge Heretics Society, Virginia Woolf proposed a "scientific" reason to explain the appearance of modern fiction and that reason was Freud:

\footnotetext{
${ }^{14}$ Letter to Fliess of October 15, 1897.

${ }^{15}$ Gilles Deleuze in Proust and Signs developed this distinction between pathos and logos. Deleuze proposed a reading of Proust in which the world of pathos contrasts " with the world of logos, the world of hieroglyphs and ideograms with the world of analytic expression, phonetic writing and rational thought" (Deleuze, 1972, p. 108).
} 
"If you read Freud you know in ten minutes some facts - or at least some possibilities which our parents could not have guessed for themselves: to read Freud was to come to know something that even scrupulous scrutiny could not divine." (Woolf, 1924, p. 504)

The new knowledge that made of Freud the catalyst of modernity in literature was of course the explicit knowledge of the unconscious. However, even more than the unconscious as a concept, I wonder if Freud's influence on literature might have more to do with the transcription of the unconscious in the practice of writing. This idea rests on the hypothesis that I have tried to explore here in my paper: the psychoanalytic mechanism generates psychical phenomena, which replay in the here and now of the analytic situation a hallucinatory mode of thinking that was at the origin of psychical reality.

To create a form of writing to describe those psychical phenomena is a challenge for the analyst who searches for an epistemological framework in order to make sense of the clinical encounter, but it is also a challenge for the writer. I believe that to put the language at work in order to create a writing of the psychical reality revealed by the analytical cure is one of the great challenge that has arisen for the writers of modern fiction, for the writers after Freud. 


\section{References}

Andersson, O. (1962) Studies in the Prehistory of Psycho-Analysis. New York, NY: Humanities Press.

Assoun, P. L. (2009). Le Freudisme. Paris, France: Presse Universitaire de France.

Deleuze, G. (2000). Proust and Signs. Minneapolis, MN: University of Minnesota Press

Derrida, J. (1976). Of Grammatology. Baltimore, MD: Johns Hopkins University Press.

Derrida, J. (1978). Writing and Difference. Chicago, IL: University of Chicago Press.

Freud, S. (1900). The Interpretation of Dreams; S.E. V.

Freud, S. (1893). Studies On Hysteria; S.E. II.

Freud, S. (1905). Three Essays on the Theory of Sexuality, S.E.VII.

Freud, S. (1911). Formulations on the Two Principles of Mental Functioning, S.E. XII.

Freud, S. (1912). The Dynamics of Transference, S.E. XII.

Freud, S. (1914) On Narcissism: an Introduction, S.E. XIV.

Freud, S. (1915a). Instincts and their Vicissitudes, S.E. XIV.

Freud, S. (1915b). Repression, S.E. XIV.

Freud, S. (1915c). The Unconscious, S.E. XIV.

Freud, S. (1915c). A Metapsychological Supplement to the Theory of Dreams, S.E. XIV.

Freud, S. (1916-1917). Introductory Lectures on Psycho-Analysis, S.E. XVI.

Freud, S. (1920). Beyond the Pleasure Principle, S.E. XVIII.

Freud, S. (1923). Two Encyclopaedia Articles, S.E. XVIII.

Gedo, J. (1977). Psychoanalytic Theory. An Exploration of Essentials. Psychoanalytic Quarterly, 46, 319-325.

Granger, G. G. (1977). Pensée formelle et Science de L'Homme. Paris, France: AubierMontaigne.

Kubie, L. S. (1947). The Fallacious Use of Quantitative Concepts in Dynamic Psychology. Psychoanalytic Quarterly, 16, 507-518.

Laplanche, J. (1993). Nouveaux Fondements pour la Psychanalyse. Paris, France: Presse Universitaire de France.

Laplanche, J., \& Pontalis, J. B. (1973). The Language of Psychoanalysis. London, UK: Karnac.

Merleau-Ponty, M. (1956). Article: Franz Brentano. In M. Merleau-Ponty (Ed.), Les Philosophes de l'Antiquité au XXè Siècle. Paris, France: La Pochotèque.

Mosès, S. (2011). Rêves de Freud Six lectures. Paris, France: L'infini Gallimard.

Safatle, V. (2011). Etre juste avec Freud: la psychanalyse dans l'antichambre de "De la grammatologie". In P. Maniglier (Eds.), Le Moment Philosophique des Années 1960 en France (pp. 395-408). Paris, France: Presse Universitaire de France.

Wollheim, R. (1991). Freud. London, UK: Fontana Press.

Woolf, V. (1924). Character in Fiction. In A. McNeillie (Ed.), The Essays of Virginia Woolf (p. 421). London, England: Hogarth Press.

Wotling, P. (2008). La Philosophie de l'Esprit Libre. Paris, France: Champs Essais. 